\title{
Performance Characteristics of Centrifugal Pump Conveying Soft Slurry
}

\author{
Mohamed F. Khali1 ${ }^{1,2}$, Sadek Z. Kassab ${ }^{2}$, Ahmed A. Abdel Naby ${ }^{2,3}$, A. Azouz ${ }^{2, *}$ \\ ${ }^{1}$ Department Mechanical Engineering, Faculty of Engineering, Lebanese International University, Beirut, Lebanon \\ ${ }^{2}$ Department Mechanical Engineering, Faculty of Engineering, Alexandria University Alexandria, Egypt \\ ${ }^{3}$ Department Mechanical Engineering, Faculty of Engineering, Beirut Arab University Beirut, Lebanon \\ *Corresponding author: azouz19680409@yahoo.com
}

Received May 02, 2013; Revised June 15, 2013; Accepted July 10, 2013

\begin{abstract}
The present experimental study deals with the effect of varying different soft slurry concentrations ranging from 0 to $18 \%$ by weight on the performance characteristic of a centrifugal pump. Experimental results are presented for pump performance (head, overall efficiency and electrical power input) as a function of the flow rate. In addition the pump performance is predicted by general empirical correlations, using the obtained experimental data as function of the soft slurry concentration used in the present study. Within the operating range of the considered parameters, the obtained results show that the head and the efficiency of a centrifugal pump with soft slurry are lower in comparison to water due to the presence of soft slurry. The head and the efficiency of a centrifugal pump decrease with increase in slurry concentration by weight and specific gravity. Power consumption on the other hand increases with the increase in soft slurry concentrations and specific gravity.
\end{abstract}

Keywords: centrifugal pump, soft slurry, empirical correlations, specific gravity, head reduction

Cite This Article: Khalil, Mohamed F., Sadek Z. Kassab, Ahmed A. Abdel Naby, and A. Azouz, "Performance Characteristics of Centrifugal Pump Conveying Soft Slurry." American Journal of Mechanical Engineering 1, no. 5 (2013): 103-112. doi: 10.12691/ajme-1-5-1.

\section{Introduction}

Centrifugal slurry pump are being used extensively for slurry pipeline transportation systems because of their capabilities to economically convey large size abrasive solids in bulk. The effect of included solids on a centrifugal pump performance is a major consideration in the pump selection and slurry system design. However, some designs of the slurry handling systems are based on the pump performance with clear water only which may lead to an insufficient use of system and even lead to the failure of the pumping system. For this reason, the accuracy of predicted head and efficiency reduction factors for a slurry pump is very important for the design and optimization of a slurry transportation system [1].

The performance characteristics of slurry pumps are poor as compared to the conventional pump, because slurry pump efficiency has influence on various factors like size and concentration of the solid particles, abrasive property of the slurry, pumping pressures, pipe diameter, reactivity between the solids and the liquid and the surfaces, viscosity of the liquid, critical velocity and slurry properties.

A designer needs to know the pump performance for handling slurry for design and operation of a slurry transportation system. It is difficult and time consuming to evaluate the performance characteristics of these pumps with all type slurries. Many investigators have proposed different correlation for the estimation of these correction factors which are dependent on solid concentration, pump design, flow rate and solid properties. These correction factors, in general, are function of flow field inside the pump due to suspended solids and additional losses due to solids.

To deduce the performance of slurry fluids from the data of water, many empirical methods using correction factors obtained from experimental results on single stage centrifugal pump. When a pump at a given speed operates on slurry instead of water, the head decreases while the power drawn increases. The flow of solids through the pump has associated hydraulic losses caused by relative motion of slurry particles (drag effect) which have greater inertia and cannot accelerate as rapidly as the carrier liquid [2]. Sellgren and Vappling [3] have investigated the effect of solid concentration for two tailings materials on the performance of a centrifugal slurry pump of a closed impeller. They observed fall in head and efficiency with increase in solid concentrations. Sellgren et al. [4] have reported that the weighted mean diameter is a better representative particle size for multi-sized slurries as compared to the median particle diameter for analyzing the pump performance. Ni et al. [5] have experimentally evaluated the effect of high delivered volumetric concentration $\left(\mathrm{C}_{\mathrm{v}}\right)$ on characteristics of a slurry pump. They conclude that high solid concentration has a strong influence on the pump head, efficiency and power consumption and this influence behaves differently with different sand size. The pump efficiency in coarse sand 
slurry service may drop almost $60 \%$ compared to that of water service, when $\mathrm{C}_{\mathrm{v}}=42 \%$. Sellg ren et al. [6] showed that the addition of clay to sand slurries has been found to reduce the pipeline friction losses, thus lowering the required energy consumption. Gandhi et al. [7] presented a methodology based on a loss analysis procedure to predict the performance of centrifugal slurry pumps handling solid-liquid mixtures.

Gandhi et al. [8] reported the performance of two centrifugal slurry pumps for three solids materials having different particle size distribution in terms of head, capacity and power characteristics. They conclude that the head and efficiency of the pump decrease with increase in solid concentration, particle size and slurry viscosity. Also they reported that the efficiency ratio is higher than the corresponding head ratio in order 2-10\%.Addie et al. [9] discussed numerical model of flow liquid and solid. They obtained the solid velocities inside an optically transparent acrylic pump using Particle Image Velocity. Pullum et al. [10] have calculated the performance reduction of the centrifugal slurry pump using Hydraulic Institute method for handling non-Newtonian coarse particle suspensions up to $38 \%$ (by volume) with mean diameters in the range of $1.1<\mathrm{d}_{50}<3.4 \mathrm{~mm}$ suspended carrier fluids. They found that the reduction in the head is the function of coarse solid concentration. Yassine et al. [11] carried a test to validate some existing correlations and they made a comparison of predicted values of $\mathrm{K}_{\mathrm{H}}$ with their experimental data. They found that the Burgess and Reizes [12] correlation gives the best comparison results between the predicted $\mathrm{K}_{\mathrm{H}}$ values and the measured ones with an error lies within the range $-33 \%$ to $+21 \%$ band and the predicted values using Kazin et al [13], correlation and Engine and Gur [14], correlation are approximately $50 \%$ to $+60 \%$ respectively, higher than the measured values this reveals a larger error band. Cave [15] showed that the head ratio might be slightly more than the efficiency ratio for a practical operating condition. Sellgren [16] showed that the head ratio was almost equal to efficiency ratio and could be treated equal to each other up to 20-25\% concentration of solids by volume. After that, the efficiency ratio drops more sharply than the corresponding head ratio.

In order to predict the performance of centrifugal slurry pumps, several investigation have proposed some theoretical and empirical correlations. Most of researches agree that clear water head and efficiency are generally lowered by the presence of solids and they introduced empirical correlations based on their experimental data to estimate the effects of the presence of solids in the pumped liquid.

An existing correlation collected from the literature is given in Table 1.

Form the above literature review; one found that there is still a margin to find a more reliable correlation or procedure for predicting head reduction factor over a wide range of physical properties of slurries and operating condition, especially soft slurry (aquatic weeds).

As can be seen from Table 1 most of authors in studies considered $\mathrm{K}_{\mathrm{H}}$ is basically a function of concentration of solids, $\left(\mathrm{C}_{\mathrm{w}}\right.$ or $\left.\mathrm{C}_{\mathrm{v}}\right)$, specific gravity of solids, $\mathrm{S}$, and representative diameter of particles $d w$ in the pumped slurry. Engine take into consideration in his analysis the impeller diameter and indicated that the head reduction factor $\left(\mathrm{K}_{\mathrm{H}}\right)$ could be better correlated with the ratio of representative diameter of particles $d_{w}$ to the outer diameter of the pump impeller, $\mathrm{d}_{2},\left(\mathrm{~d}_{\mathrm{w}} / \mathrm{d}_{2}\right)$. However, in the present study, it observed that most of correlations valid only when the specific gravity of solids greater than specific gravity of water, $(S>1)$.

The objective in the present study is to characterize the effect of soft slurry (weeds) on the performance of centrifugal slurry pump for various aquatic weeds experimentally. The second objective of this study is to provide a new correlation to predict the head reduction factor due to presence of soft slurries in the pump.

\section{Expenimental Apparatus and Instrumentation}

The experimental data are obtained by conducting experiments using a specially designed and fabricated experimental facility.

A schematic diagram and a photograph of the pumping system designed and used in the present study are shown in Figure 1 and Figure 2 respectively.

The test rig consists of a loop which incorporates a steel tank (1) of $1 \mathrm{~m}$ width, $1.5 \mathrm{~m}$ length and $1 \mathrm{~m}$ height divided into two parts. The first part is the mixing part (1m width, $0.75 \mathrm{~m}$ length and $1 \mathrm{~m}$ height) and is used to mix the water hyacinth with water. The second part is the compensation part (1m width, $0.75 \mathrm{~m}$ length and $1 \mathrm{~m}$ height) and is used to receive the pump discharge and delivers a compensating amount of slurry back to the mixing part through the screen in the buffer plate (4) in order to keep a constant mixture level. The transfer pump (2) supported inside the mixing part of the steel tank by a mechanism attached to a steel frame work (9). A Perspex inlet cone shape (3) is attached to the pump suction inlet to increase the pump ability to suck the mixture of the water- water hyacinth. A Perspex pipe (8) is placed at the end of the pump delivery piping system to visualize the pump output flow mixture. Pump flow rate is measured using turbine flow meter (7). A frequency inverter is employed in order to have the ability to control and varied the pump operating speed, if needed. There is a 15 minutes period time interval between the end of the experiments and the use of the measuring instruments. This period of time is employed to insure the steady state conditions.

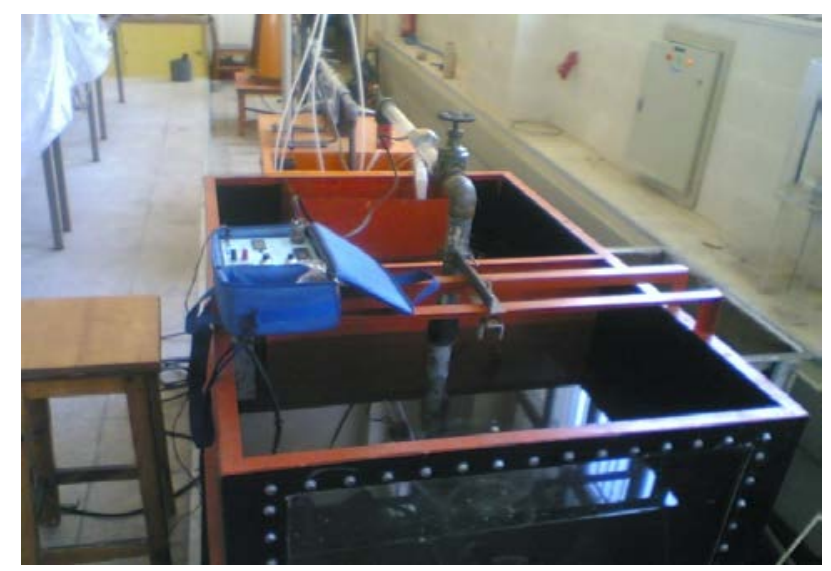

Figure 1. Photo. of experimental setup 


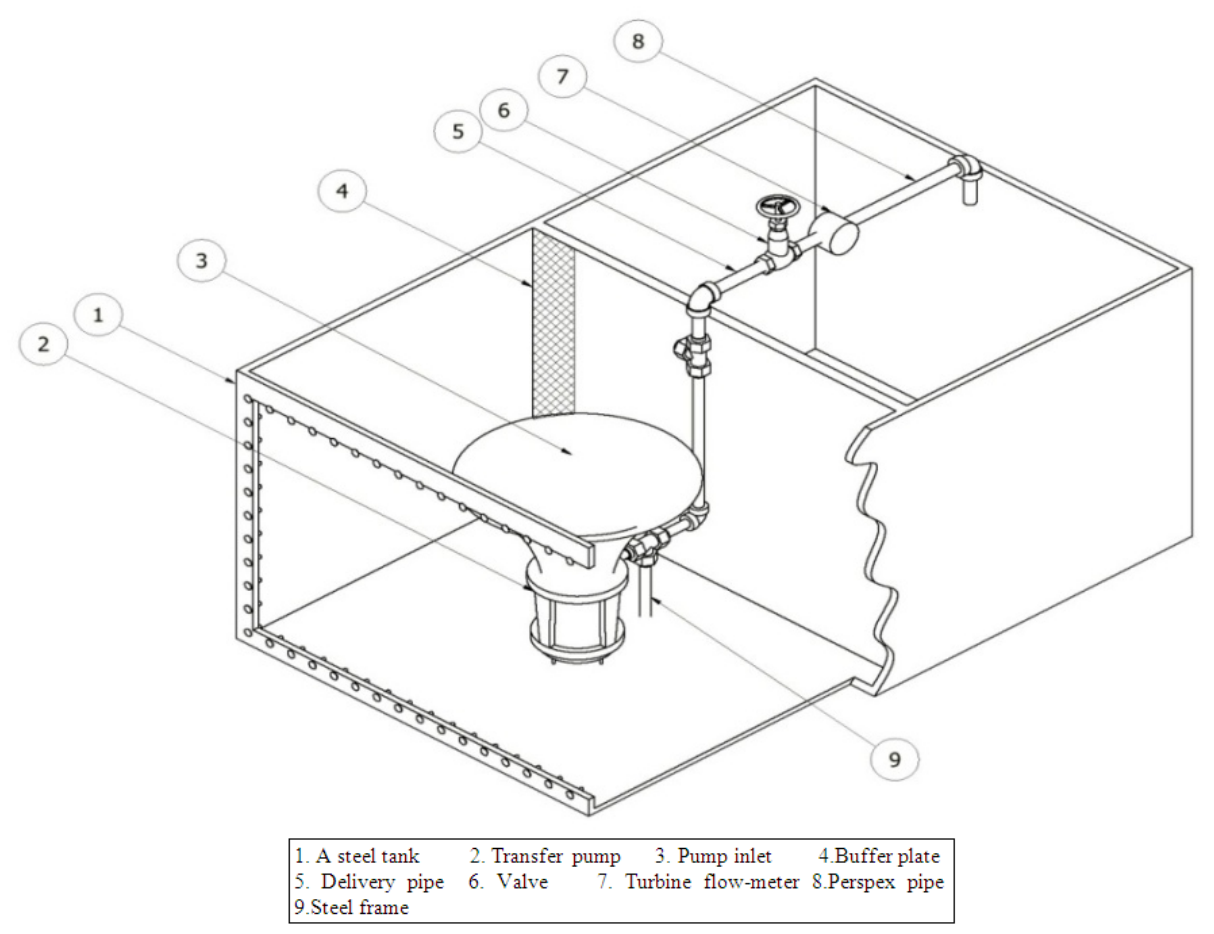

Figure 2. Schematic diagram of experimental setup

Soft slurry for the tests was prepared before test experiments by using the recovery hydraulic system which cutting the water hyacinth and cattails (solids used in twophase flow) to s mall pieces and then adding the required quantities of cutting water hyacinth and water [19, 20], circulating the mixed before tests always keeping the slurry in a well-mixed state before and during experiments.

The slurry is drawn from the tank by the pump and returned after circulation through the mesh in the buffer plate directly to the tank. One valve was installed at the delivery pipe. A strainer was installed on the delivery side between the delivery pipe and $U$ manometer to avoid clogging of water hyacinth. The pump impeller type used in the present study is the semi-open type. In addition, the centrifugal pump specifications are given in Table 3 .

The shaft power of the pump calculating as,

$$
P_{s h}=I \cdot V \cdot p f
$$

Table 1. Existing correlations for the head reduction factor, $\mathrm{KH}$, in the lite rature

\begin{tabular}{|c|c|c|c|c|}
\hline No & Author & Year & Correlation & \\
\hline 1 & Vocadlo et al.[17] & 1974 & $K_{H}=\frac{C_{V}}{S_{m}}(S-1)\left[0.167+\varphi \sqrt{\frac{d_{50}(S-1)}{d_{2}}}\right]$ & (2) \\
\hline 2 & Cave [15] & 1976 & $K_{H}=0.0385(S-1) \frac{S+4}{S} C_{W} \ln \left(\frac{d_{50}}{22.7}\right)$ & (3) \\
\hline 3 & Burgess and Reizes[12] & 1976 & $\begin{array}{l}K_{H}=1-\left(1-C_{W}\right)^{n} \\
n=S\left(-0.1734 d_{50}^{2}+0.365 d_{50}+0.027\right), d_{50}(\mathrm{~mm})\end{array}$ & (4) \\
\hline 5 & Sellgren[16] & 1979 & $K_{H}=0.32 C_{W}^{0.7}(S-1)^{0.7} C_{D}^{-0,25}$ & (5) \\
\hline 6 & Gahlot et al.[18] & 1992 & $K_{H}=0.00056(S-1)^{0.72} \frac{S+3}{S} C_{W} \ln \left(50 d_{w}\right)$ & (6) \\
\hline 7 & Kazim et al.[13] & 1997 & $K_{H}=0.13 C_{W} \sqrt{S-1} \ln \left(\frac{d_{W}}{20}\right)$ & (7) \\
\hline 8 & Engine and Gur[14] & 2001 & $K_{H}=0.11 C_{W}(S-1)^{0.64} \ln \left(\frac{d_{W}}{22.7}\right)$ & (8) \\
\hline 9 & Engine and Gur[2] & 2003 & $K_{H}=2.705 C_{W}(S-1)^{0.64}\left(\frac{d_{W}}{d_{2}}\right)^{0.313}$ & (9) \\
\hline \multirow{2}{*}{10} & \multirow{2}{*}{ Yassine et al [11] } & \multirow{2}{*}{2010} & $H_{R}=1.8369 C_{w}^{2}-0.742 C_{w}+1$ at $\mathrm{QEP}$ & (10) \\
\hline & & & $\eta_{R}=1.639 C_{w}^{2}-1.005 C_{w}+1$ at $\mathrm{QEP}$ & (11) \\
\hline
\end{tabular}




\subsection{Properties of Material Used}

The materials used in the present study are aquatic weeds (water hyacinth and cattails). Table 2 shows the specific gravity and the reprehensive particle size in terms of weighted mean $\left(\mathrm{d}_{\mathrm{w}}\right)$ and median diameter $\left(\mathrm{d}_{50}\right)$ for using materials. The particle size distributions of weeds were determined by sieve analysis. A sample of $1000 \mathrm{~g}$ of dry weed was used for sieving. The weighted mean diameter $\left(d_{w}\right)$ of weed was calculated. The weighted mean particle diameter, $d_{w}$, is defined as follows.

$$
d w=\sum_{i=1}^{k} X_{i} d_{i}
$$

Where $\mathrm{k}$ is the number of sieve groups, in which the total sample was divided, $X_{i}$ is the weight fraction of solids retained on the ith size group, and $\mathrm{di}$ is the arithmetic mean of two successive sieve openings. The mass median $\left(d_{50}\right)$ is the sieve size through which the dry weeds sample $50 \%$ by weight passed. Engine and Gur [2] showed that, when the particle size is represented by the weighted mean particle diameter $\left(\mathrm{d}_{\mathrm{w}}\right)$ more than two particle size groups are considered and weight is given to each group. Since the individual contribution on of each size group is reflected better using $d w$ rather than $d_{50}$.

Table 2. Physical properties of aquatic weedused

\begin{tabular}{|c|c|c|}
\hline Physical properties & Water hyacinth & Cattails \\
\hline Specific Gravity & 0.096 & 0.15 \\
\hline Weighted mean diameter $\mathrm{d}_{\mathrm{w}}$ ),mm & 3 & 5.5 \\
\hline
\end{tabular}

Table 3.Centrifugal pumpspecifications and performance curve

\begin{tabular}{|c|c|c|}
\hline Pump part & \multicolumn{2}{|c|}{ Specification } \\
\hline Pump model & EGR100M & \\
\hline 1-Impeller & & Type \\
\hline & No of vanes, $\mathrm{z}$ & 6 \\
\hline & Outlet diameter & $38(\mathrm{~mm})$ \\
\hline & Inlet diameter & $101.6(\mathrm{~mm})$ \\
\hline 2-Casing & Type & Single volute \\
\hline 3-Manufacture & Operat ing Speed & $2900(\mathrm{rpm})$ \\
\hline & Discharge Capacity & $15\left(\mathrm{~m}^{3} \mathrm{~h}\right)$ \\
\hline & Shut-off Head & $18.55(\mathrm{~m})$ \\
\hline
\end{tabular}

\subsection{Test Method}

In order to study the effects of the suspended soft slurry on the centrifugal pump characteristics, tests were conducted with mixtures of water and aquatic weeds at different concentration for weeds, $\mathrm{C}_{\mathrm{w}}$, ranging from 0 to $18 \%$. Measurements of pump characteristics with clear water were carried out both before and after each mixture test. Following the completion of the pump test with water a pre-calculated weight of weeds was slowly added to water in the mixing tank. The mixture was kept in circulation for approximately $15 \mathrm{~min}$. before starting data collection. For various settings of the delivery valve, the flow rate and the delivery pressures were recorded at constant pump speed. The densities of the weeds were determined using a mixture sample. Steps were repeated for weeds concentrations $\left(\mathrm{C}_{\mathrm{w}}\right)$ ranging from 0 to $18 \%$.

The uncertainties in head, capacity, speed, shaft power and efficiency are $1.25 \%, 0.75 \%, 2 \%, 1.1$ and $1.5 \%$ respectively.

\section{Results and Discussions}

Figure 3, Figure 4 and Figure 5 show the variation of pump performance parameters (head, efficiency and power) with pump flow rate at various values of slurry concentration ratio by weight. These results are for constant pump speed, the head and efficiency for the pump handling soft slurries are lower than those for handling water as shown in Figure 3 and Figure 4 but the power input for handling soft slurries is higher than that for handling water as shown in Figure 5. Moreover, as concentration ratio increases, pump head and efficiency decrease while pump input power increases. The drop in the pump performance parameters may be due to change in fluid properties which cause increasing in disk friction losses and drag effect over impeller and volute. The disk friction efficiency was increased by the use of the slurry because the drag effect for the rotating disk friction. The hydraulic efficiency was increased due to increasing in friction losses. As the result the energy needed to maintain the weeds in suspension and motion increases with increase in concentration of weeds.

To study the effect of slurry specific gravity on the performance of slurry pump, Figure 6, Figure 7 and Figure 8 show the variation of pump performance parameters (head, efficiency and power) with pump flow rate at various values of slurry specific gravities. it is observe that the pump head and efficiency for the pump handling soft slurries (weeds) decrease with the increasing in the specific gravity while, the shaft power input increases as specific gravity increases.

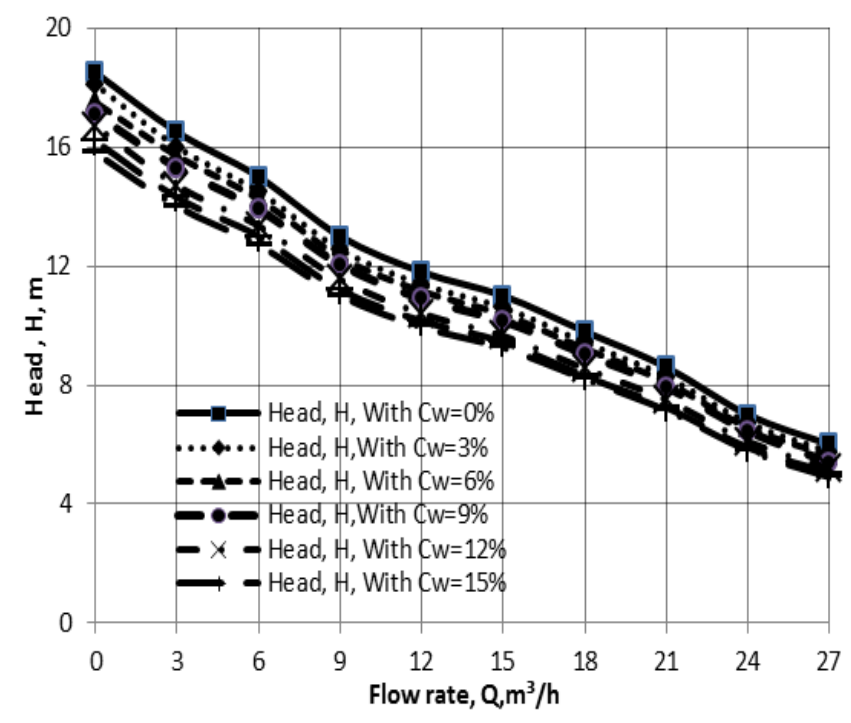

Figure 3. Headflow rate characteristics of the pump at different concentration 


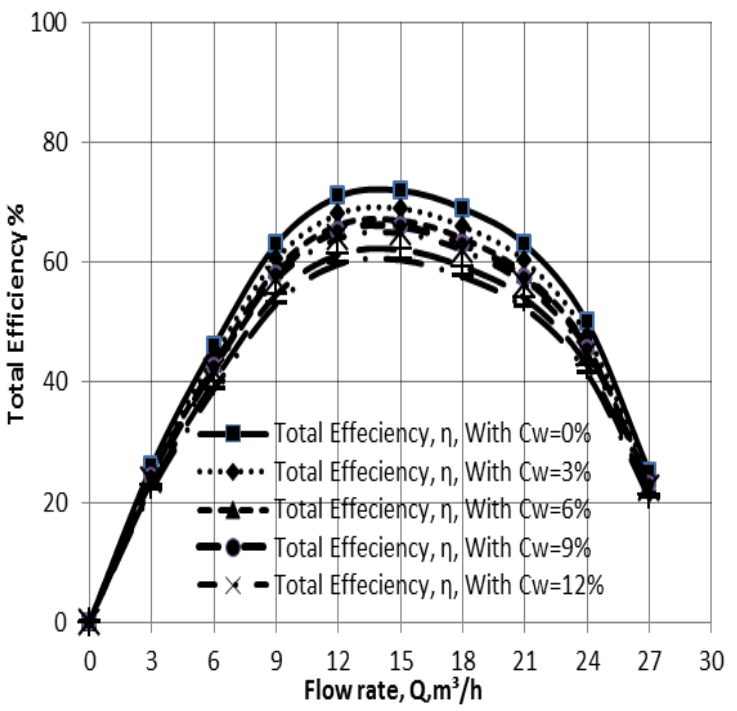

Figure 4. Efficiency-flow rate characteristics of the pump at different concentration

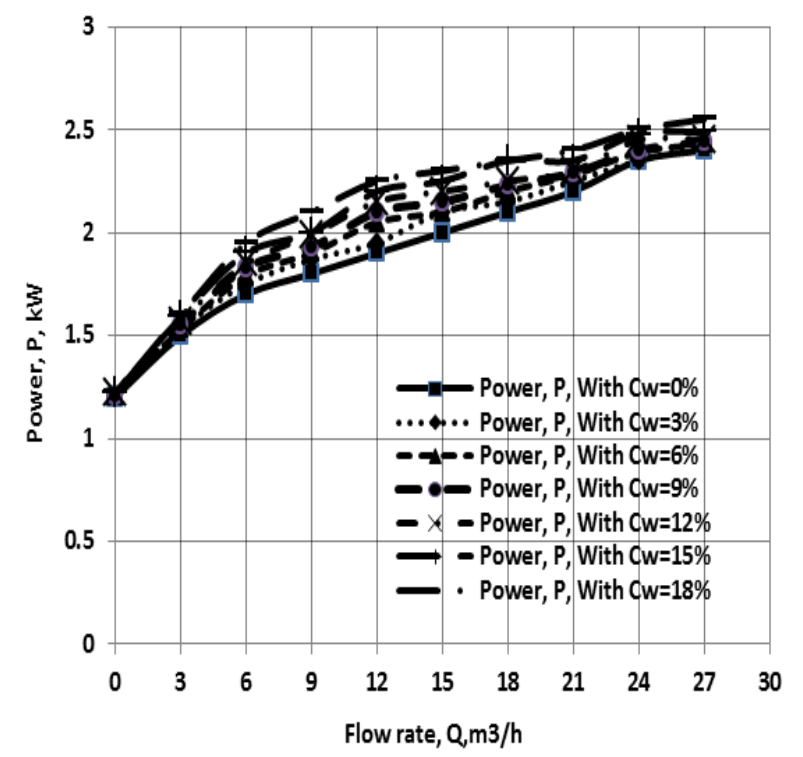

Figure 5. Power-flow rate characteristics of the pump at different concentration

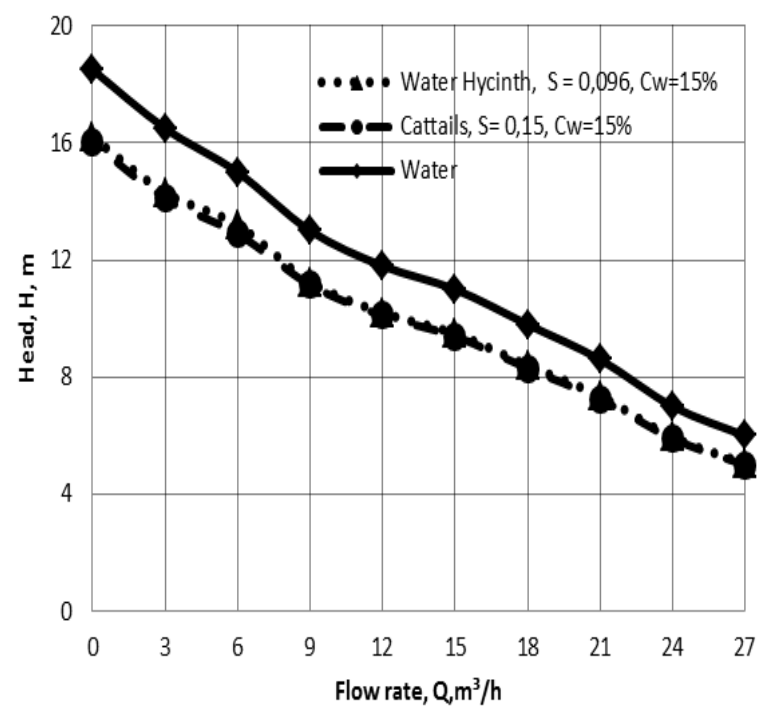

Figure 6. Head- flow rate characteristic of pump at different slurries (soft material)

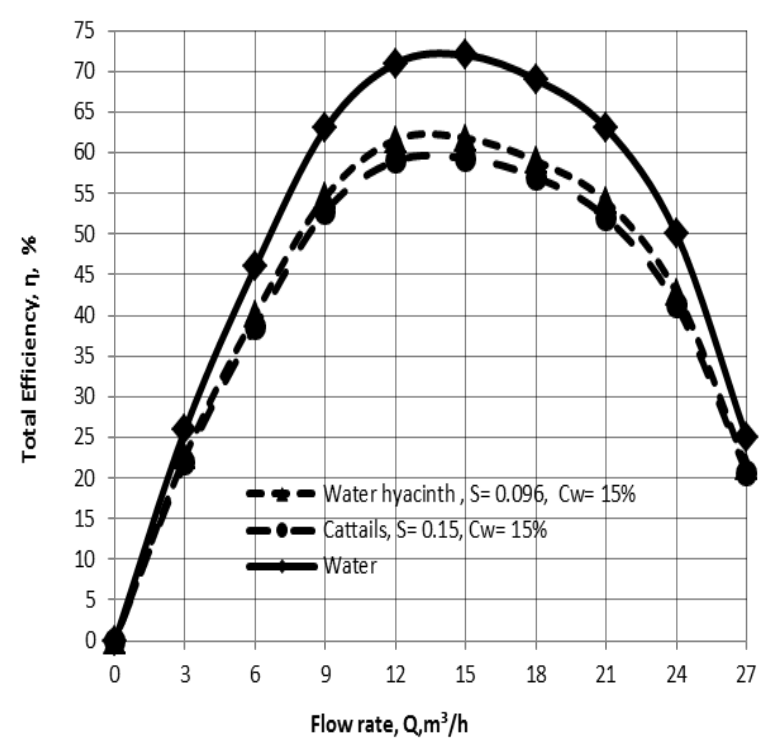

Figure 7. Efficiency-flow rate characteristic of pump at different slurries (soft material)

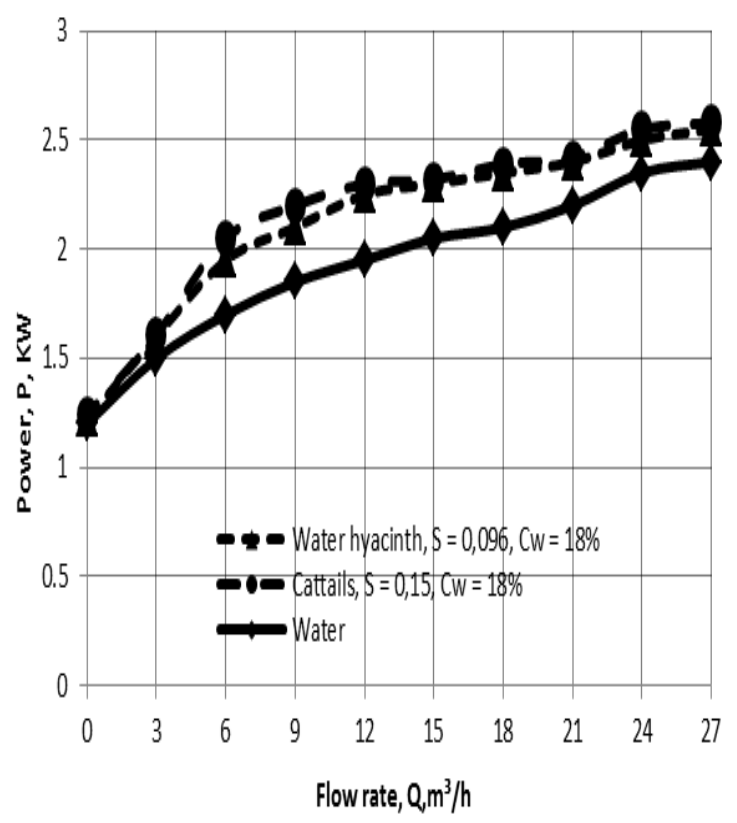

Figure 8. Power - flow rate characteristic of pump at different slurries (soft material)

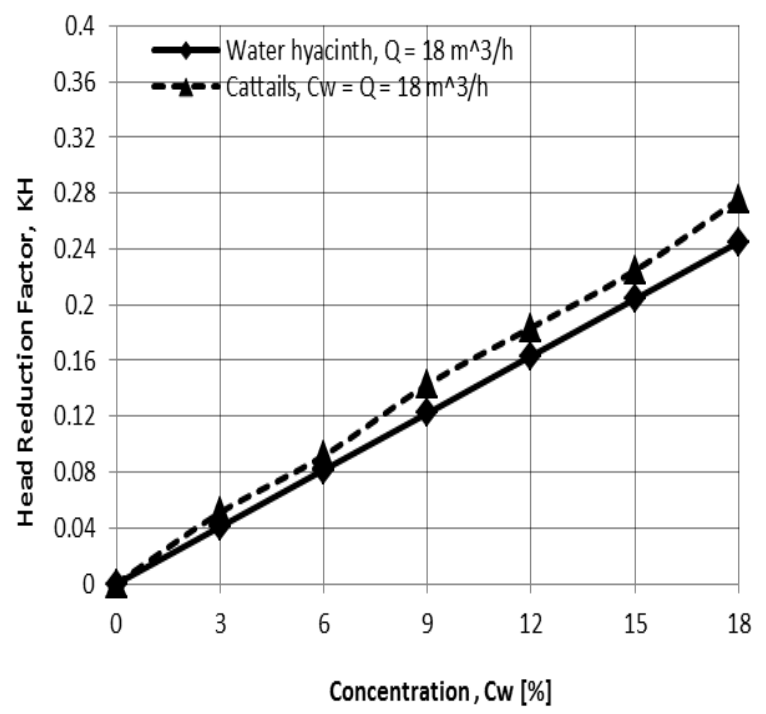

Figure 9. Variation of head reduction factor with concentration 


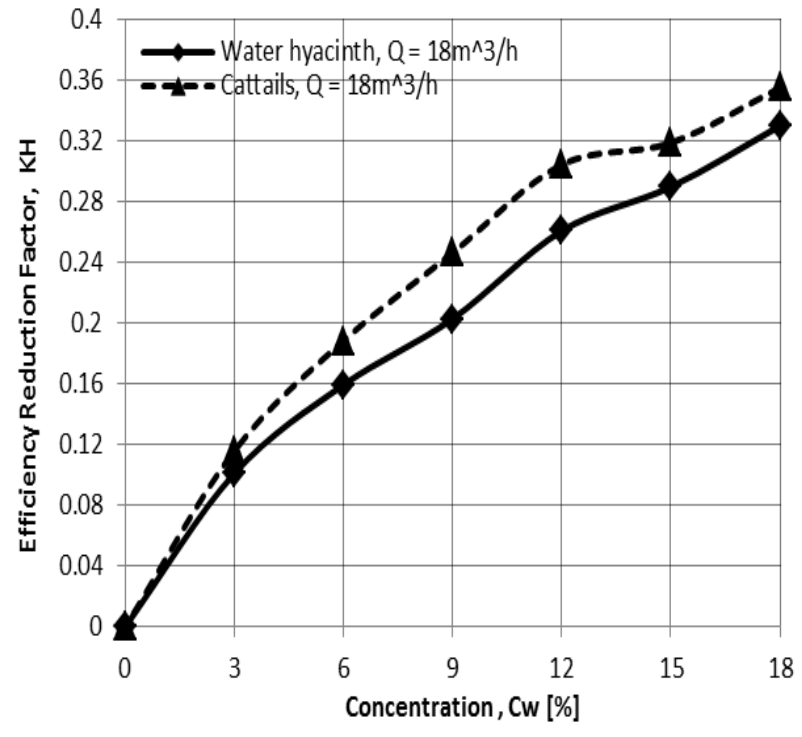

Figure 10. Variation of efficiency reduction factor with concentration

Figure 9, Figure 10 present the Variation of head reduction factor and efficiency reduction factor with concentration ratio at various values of specific gravity, $\mathrm{S}$. These results are for constant flow rate and pump speed. Figures 9 and 10 show that as the concentration, $\mathrm{C}_{\mathrm{w}}$ increases $K_{H}$ and $K_{\eta}$ increase. Moreover, as specific gravity, $S$, increases, $K_{H}$ and $K_{\eta}$ also increase.

Figure 11 and Figure 12 show that the variation of head and efficiency reduction factors, $K_{H}, K_{\eta}$ with the concentration, $\mathrm{C}_{\mathrm{w}}$, at various values of pump flow rate, $\mathrm{Q}$, and constant pump speed, for a given concentration of weed, the figures show that the pump performance reduction factors were independent of pump flow rate.

In order to reveal the relationship between the pump performance reduction factors with various concentration ratios, a typical comparison could be made using the experimental data, Figure 13 shows the head and efficiency reduction factors at the best efficiency point (BEP) against concentration ratio. As the concentration ratio is less than $11 \%$, the head reduction factor is less than efficiency reduction factor, as the concentration ratio is up, the head reduction factor become more than the efficiency factor. The reason for this is may be that the drag effect rises with increasing the concentration ratio. This fact seems to reveal that the drag loss es effect on the pump performance reduction factor is more influence than the disc friction losses in low concentration ration (less than $11 \%$ ).

Engine and Gur [14] stated that no agreement on the relation between the head and efficiency reduction factors for a given pump flow rate and pump speed in the present study, it has been observed that the deviation between two quantities is within $\pm 2 \%$ and can be taken considered that the two quantities are equal to each other.

\section{Empirical Correlation}

The efficiency reduction, $\mathrm{K}_{\eta}$ of a slurry pump has been reported by some earlier authors $[1,15,17]$, to be nearly equality the corresponding head reduction factor, $K_{H}[14]$, so, the correlation given in the present study only predict head reduction factor, $\mathrm{K}_{\mathrm{H}}$, to obtain pump performance characteristics in slurry services.
Centrifugal slurry pump reduction factor, $\mathrm{K}_{\mathrm{H}}$, is predicted by a general empirical correlation, using the obtained experimental data, as function of the specific gravity, $\mathrm{S}$, representative particle diameter, $\mathrm{d}_{\mathrm{w}}$, and concentration ratio, $\mathrm{C}_{\mathrm{w}}$. The choosing parameters are those used in the present study were presented and discussed in the previous sections. The Procedure is as follows:

The empirical formula for the Centrifugal slurry pump reduction factors, $\mathrm{K}_{\mathrm{H}}$, is assumed in the form of power function for the operating conditions. These parameters are specific gravity, $\mathrm{S}$, and concentration ratio, $\mathrm{C}_{\mathrm{w}}(\%)$ and representative particle diameter, $\mathrm{d}_{\mathrm{w}}(\mathrm{mm})$

Therefore, when pumping slurries, the performance reduction factors of a slurry pump for a constant flow and rotary speed can be defined as,

$$
K_{H}=f n\left(C_{w}, S, d_{w}\right)
$$

To find the empirical formula for the performance reduction factors is assumed in the form of power function for the previous parameter $\left(\mathrm{C}_{\mathrm{w}}, \mathrm{d}_{\mathrm{w}}\right.$ and $\left.\mathrm{S}\right)$

$$
K_{H}=A C_{w}^{b} S^{d} d_{w}^{e}
$$

Appling the regression to the above equations, the constants are obtained as,

$$
K_{H}=0.0236 C_{w}^{0.7754} S^{0.2358} d_{w}^{0.1426}
$$

The average deviation between predicted $\mathrm{K}_{\mathrm{Hc}}$, and experimental $\mathrm{K}_{\mathrm{Hexp}}$, results is 0.038 and a mean deviation is 0.0697 .

Figure 14 shows the variation of the predicted, using the empirical correlation with the corresponding experimental under various operating condition. Cons equently, the scatter of the presented point around the equality line is an indication of the deviation between the two sets of pump reduction factors. The error bends in the prediction of head reduction factor lies with in the range of $\pm 10 \%$.

\section{Conclusions}

Within the operating range of the present experimental study and from the presented results and related discussions the following conclusions can be deduced:

1. The slurry pump head and slurry pump efficiency are decreased while the shaft power is increased in comparis on to those with clear water.

2. The efficiency reduction factor is slightly less than head reduction factor and can be assume to be equal to the head reduction factor

3. Empirical correlation, cover particle operating conditions are obtained for the slurry pump performance reduction factor handling soft slurry (weeds) and show reasonable agreement with the experimental data.

\section{Nomenclatures}

$$
\begin{aligned}
& \mathrm{C}_{\mathrm{v}}=\text { concentration by volume } \\
& \mathrm{C}_{\mathrm{w}}=\text { concentration by weight } \\
& \mathrm{C}=\text { drag coeffic ient } \\
& \mathrm{d}_{2}=\text { impeller exit diameter }
\end{aligned}
$$


$\mathrm{d}_{50}=$ mass median part icle diameter

$\mathrm{d}_{\mathrm{w}}=$ weighted mean particle diameter

$\mathrm{H}_{\mathrm{s}}=$ pump total head with slurry

$\mathrm{H}_{\mathrm{w}}=$ pump total head with clear water

$\mathrm{H}_{\mathrm{r}}=$ head ratio

$\mathrm{I}=$ current absorbed by pump motor
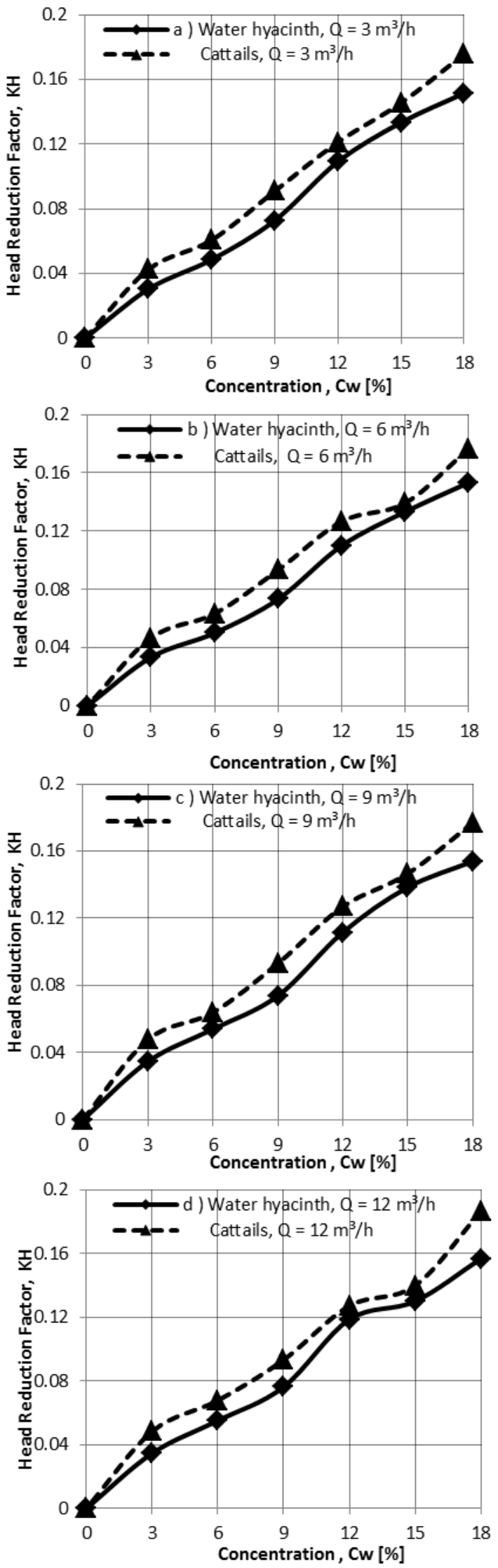

$\mathrm{K}_{\mathrm{H}}=$ Head reduction factor

$\mathrm{K}_{\eta}=$ efficiency reduction factor

$\mathrm{P}_{\mathrm{sh}}=$ pump shaft power

$\mathrm{S}=$ specific gravity of slurry

$\mathrm{V}=$ voltage across the pump motor

$\eta_{\mathrm{R}}=$ efficiency ratio
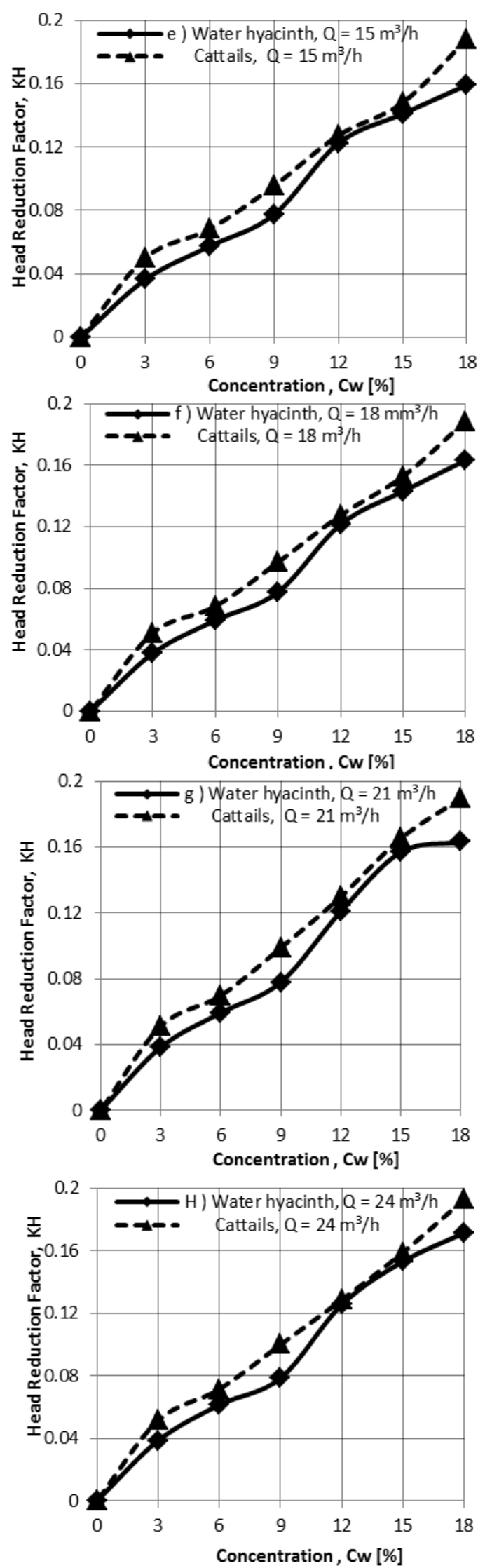

Figure 11. Head reduction factor - concentration ratio at different flow rate 

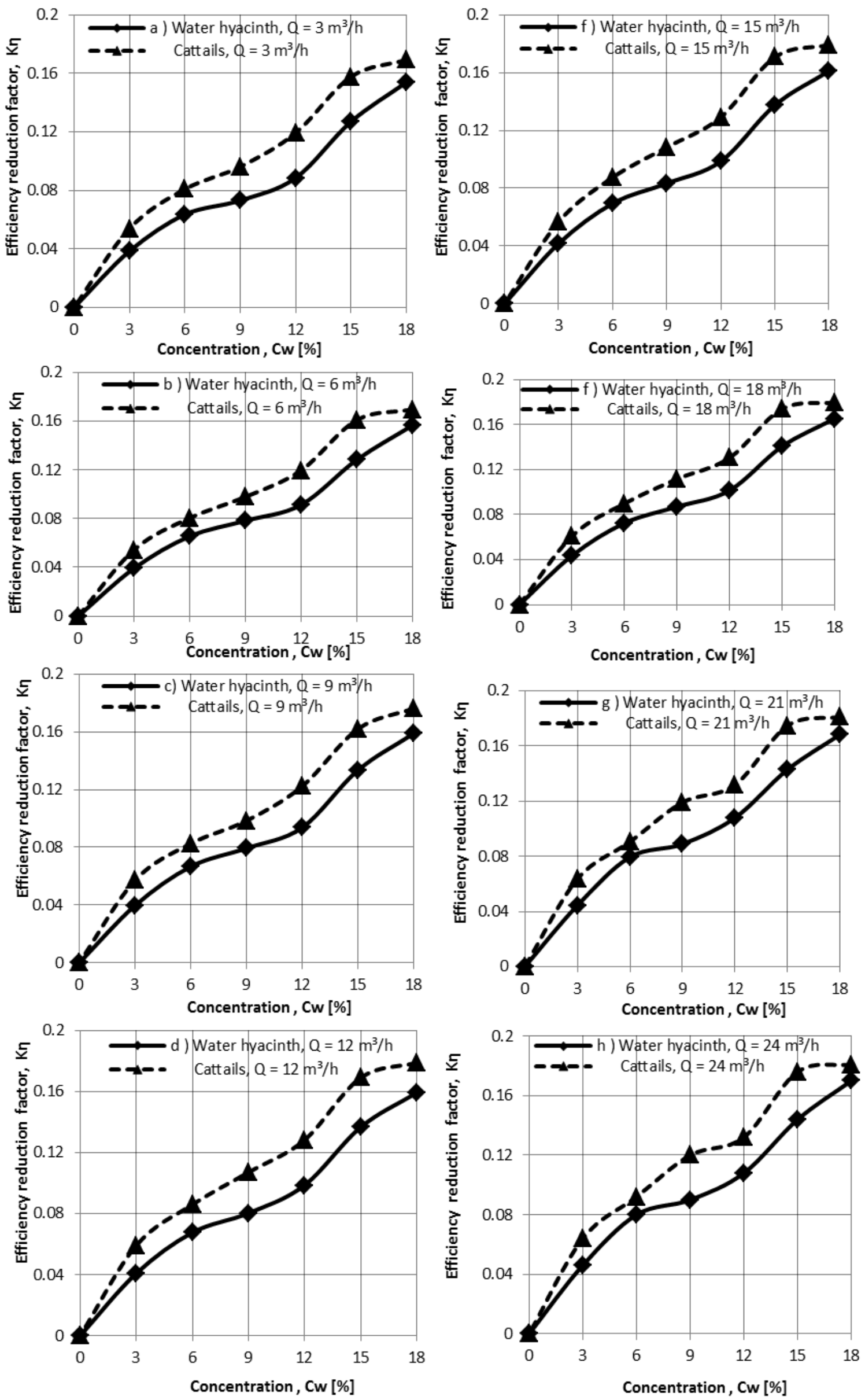

Figure 12. Efficiency reduction factor - concentration ratio at different flow rate 

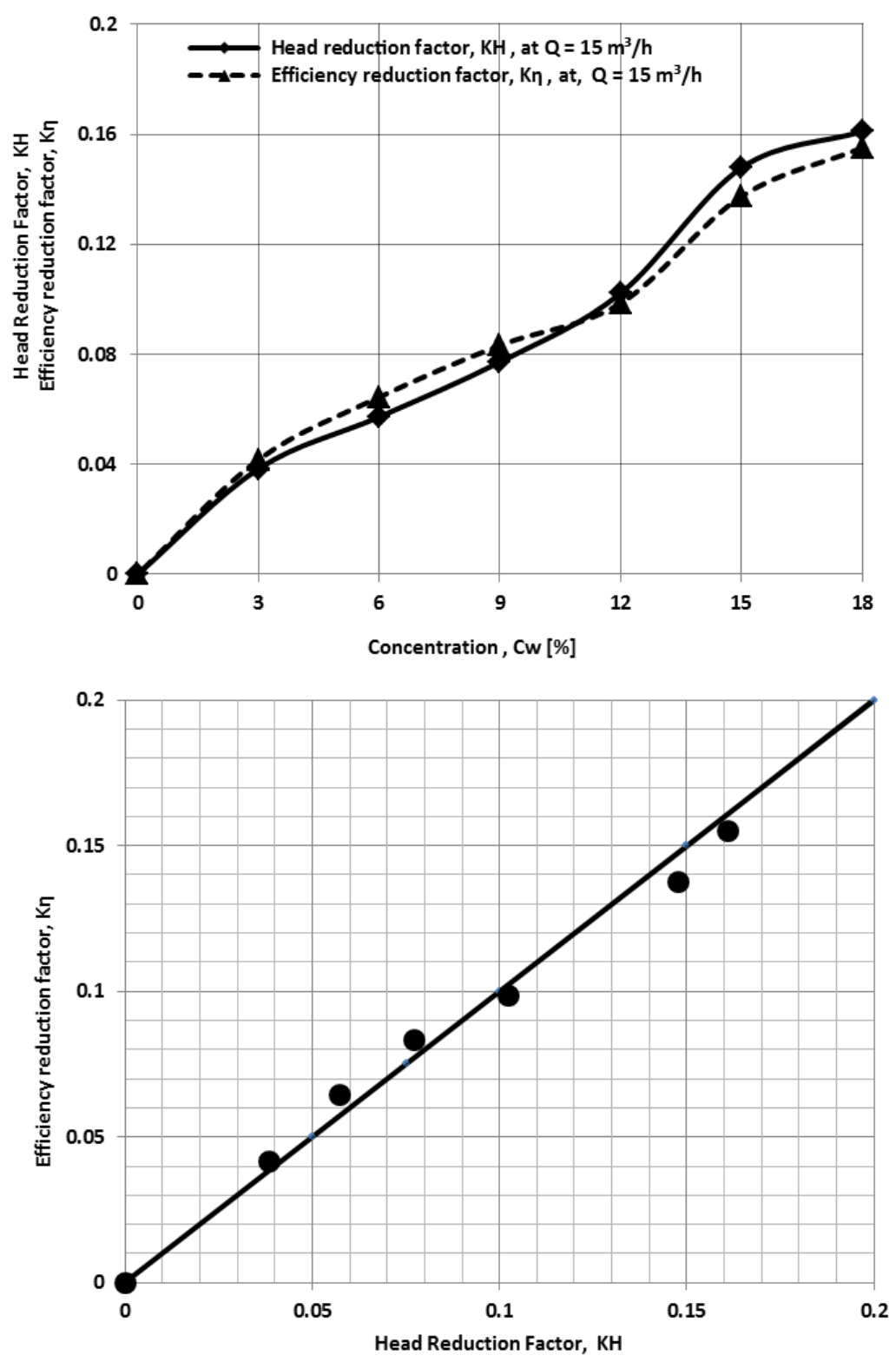

Figure 13. Comparison between head and efficiency reduction factor
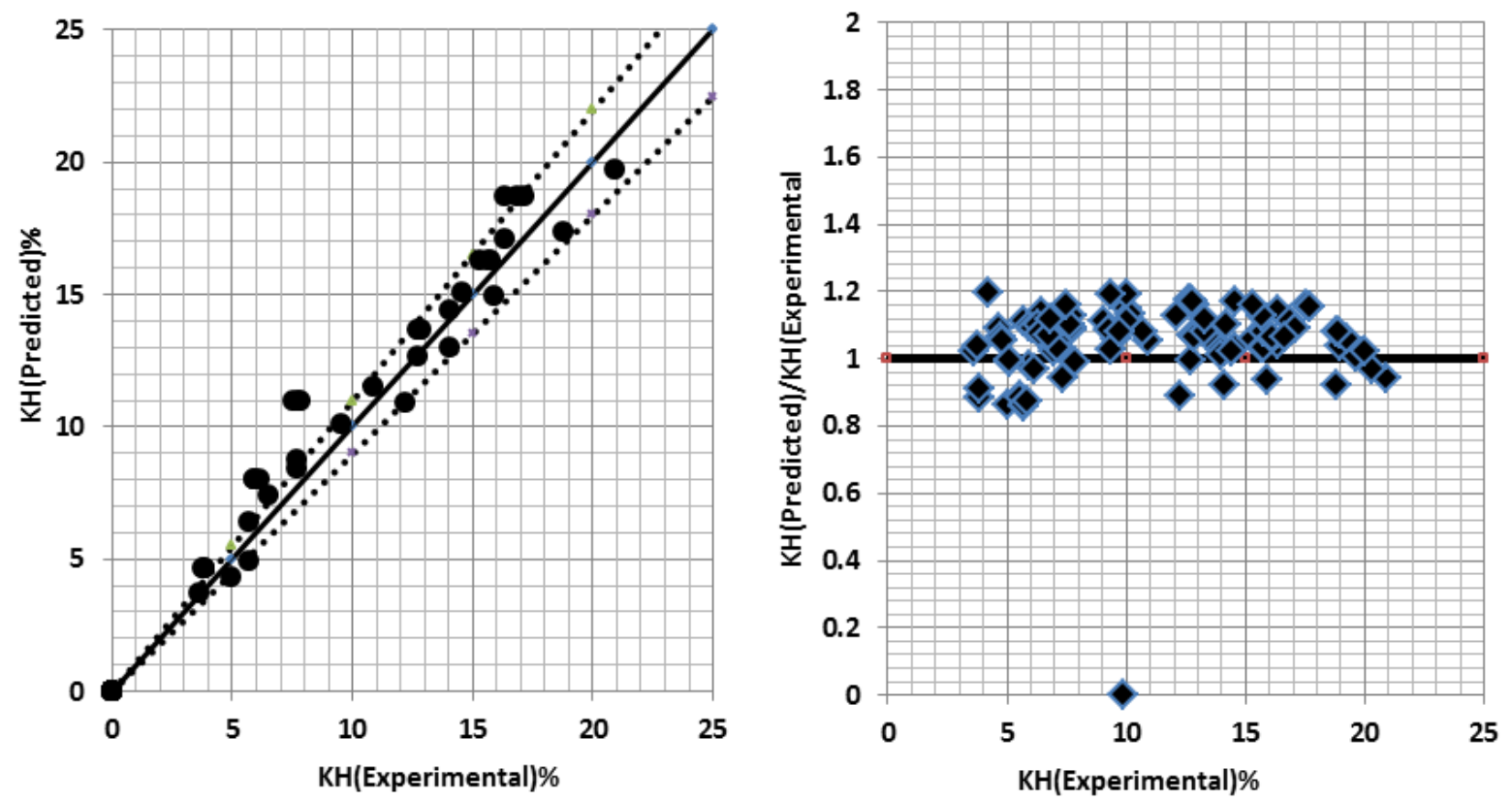

Figure 14. Comparison between predicted and experimental head reduction factor, $\mathrm{K}_{\mathrm{H}}$ 


\section{References}

[1] Stepanoff, A.J., Centrifugal and axial flow pumps theory design and application, $2^{\text {nd }}$ ed, John wilay and sons, New York.1958.

[2] Engin, T. and Gur, M. "Performance characteristics of a centrifugal pump impeller with running tip clearance pumping solid-liquid mixtures". Journal of Fluids Engineering (Transactions of the ASME). 123(3), 532-538. 2001.

[3] Sellgren, A. and Vappling, L. "Effects of highly concentrated slurries on the performance of centrifugal pumps", Intemational symposium on slurry flows, ASME-FED, 38, 143-148.1986.

[4] Sellgren, A., Turner, T.M. and Addie, G.R, Determination of the effect of solids on centrifugal slurry pumps, Fifth annual AIME Regional Phosphate Conference, Lokeland, Florida, USA.1990.

[5] Ni, F., Vlasblom, W.J., and Zwartbol, A., Effect of high solid concentration on characteristics of a slurry pumps, Hydrotransport 14, BHRA Fluid Engg. Maastricht, the Netherlands, 141-149. 1999.

[6] Sellgren, A., Addie, G. and Scott, S. "The effect of sand-clay slurries on the performance of centrifugal pumps" The Canadian J. Chemical Engg., 78, 764-769. 2000.

[7] Gandhi, B.K., Singh, S.N. and Seshadri, V. "Improvements the prediction of performance of centrifugal slurry pumps handling slurries", Proc. Instn, Indian J Mech. Engrs., 214 Part A, 473-486. 2000.

[8] Gandhi, B.K., Singh, S.N. and Seshadri, V. "Performance characteristics of Centrifugal slurry pumps", ASME J. Fluid Engg., 123, 271-280. 2001.

[9] Addie,R., Kadambi, J. R. and Robert V., Design and application, slurry pump technology, ASME Fluids engineering summer conference Houston, Texas, June 19-23. 2005.

[10] Pullum, L. J., Graham, W., and Rudman,M., Centrifugal pump performance calculations for homogeneous and complex heterogeneous suspensions", $17^{\text {th }}$ Intemational conference on the hydraulic transport of solids, the southern African Institute of Mining and Metallurgy and the BHR group. 2007.

[11] Yassine, K. C., Hammoud, A. H., and Khalil, M. F., Experimental investigation for centrifugal slurry pump performance, in Proceeding in ICFD 10, Ain Soukhna, Egypt, December 16-19. 2010.

[12] Burgess, K., E., and Riezes, S., A. "The effect of sizing, specific gravity and concentration on the performance of centrifugal slurry pump" Proc. Inst. Mech. Eng., 190, 391-399. 1976.

[13] Kazim, K., Meiti, B., and Chand, P., "A correlation to predict the performance characteristics of centrifugal pumps handling slurries" Proc. Instn. Mech. Engrs., 21A, 147-157. 1997.

[14] Engine, T. and Gur, M., "Comparative evaluation of some existing correlations to predict head degradation of centrifugal slurry pumps", J. of Fluids Engineering, 125, 149-157. 2003.

[15] Cave, I., Effects of suspended solids on the performance of centrifugal pumps, In Proceeding Hydrotransport-4, BHRA Fluid Engineering, paper H3, 35-52. 1976.

[16] Sellgren, A., Performance of centrifugal pumps when pumping ores and industrial minerals, In Proceeding Hydrotransport-6, BHRA Fluid Engineering, paper G1, 291-304. 1979.

[17] Vocadlo, J., Koo, J., and Prang, A., Performance of centrifugal pumps in slurry services, In Proceeding Hydrotransport-3, BHRA Fluid Engineering, paper J2, 17-32. 1974.

[18] Gahlot, V., Seshadri, V. and Malhotra, R. " Effects of density, size distribution and concentration of solids on the characteristics of centrifugal pumps" Trans. ASME J. Fluid Eng., 114, 386-389. 1992.

[19] Azouz, A., Performance of a pumping system handling Nile water hyacinth under variable conditions, $\mathrm{PhD}$, Alexandria University. 2012.

[20] Azouz, A., Khalil, M.F., Kassab, S.Z. and Abdel Naby A.A. Performance of a pumping system handling Nile water hyacinth, LAP LAMBERT, Academic Publishing, Deutschland, Germany, 2012. 